\title{
Assessment of External Spatial Vulnerability of Mountain Cities under Climate Change: Zhao Tong Case Study, China
}

\author{
ZHAO Kai Xi, College of Landscape Architecture, Beijing Forestry University, Beijing, China \\ Li Chi, College of Landscape Architecture, Beijing Forestry University, Beijing, China
}

\begin{abstract}
This paper discusses mountain cities of vulnerability from application of the driver-pressure-stateimpact-response (DPSIR) framework. Take Zhao Tong, as an example. Firstly, with the aid of DPSIR model, three factors both social - economic - natural, the target layer is decomposed into driving force, pressure, status, impact and response rule of five layers, the four indexes to construct the evaluation index system. Secondly, from the exposure, sensitivity and adaptability of three factors, comprehensively selected 26 evaluation factors to construct the ecological vulnerability evaluation system. The spatial principal component analysis (PCA) method was applied to extract the weights of the factors for constructing the evaluation system. Finally, ecological vulnerability of Zhao Tong was evaluated by combining the ecological vulnerability assessment theory and the spatial superposition method. The results showed that the vulnerability in the northern and southwestern parts of Zhao Tong mainly belongs to the weak intensity, and the land type is mainly mountainous and hilly areas with sparse population distribution. Secondly, Zhao Tong is more vulnerable to high disaster risk areas in the urban fringe affected by climate change than other areas. Finally, the corresponding elastic planning intervention is applied to the urban spatial units with different vulnerability characteristics.
\end{abstract}

\section{Keywords}

Urban vulnerability, Mountainous city, DPSIR

\section{Introduction}

Mountain area is an important part of human settlement space system. The complexity of regional environment, the closure of traffic conditions and the backwardness of economic development determine the particularity of mountain human settlement environment construction (Li,2014). Because of the complex terrain and the large relative height difference, mountain city is easy to form a wellscattered and rich urban landscape, but also because of the fragile geological environment, it is the region of geological disasters. Affected by climate change, the hazards of geological disasters in mountain towns are becoming more and more obvious. Nowadays, vulnerability assessment and resilience planning are one of the problems that must be solved in the development of mountain cities. The quality of urban outer space is directly related to the quality of urban space and affects the development of the city. Mountain cities have the characteristics of strong correlation with the external environment. Due to the complexity of mountain terrain, urban construction is different from that of plain cities. The layout of 
mountain cities is flexible and changeable, and the environmental characteristics determine the urban characteristics. Therefore, it is very important to carry out the vulnerability assessment of the external environment of mountain cities for urban development.

Huang and Peng (2017) demonstrated the transition from block opening to space sharing in mountain cities, including the transformation of planning concepts and the roles of relevant subjects. In addition, GIS technology can also be used to identify the spatial form of mountain cities, construct landscape security pattern(Huang et al., 2019; Yu et al., 2009), sort out the status and history of mountain cities, classify mountain types according to geological structure or comprehensive natural factors, and identify the core factors that affect the change of mountain cities and their relationships based on time context. Combined with relevant data, a system model is established to predict the future trend of change (Li et al.,2016), and the efficient utilization of underground space in mountain cities is emphasized (Wang,2015), so as to put forward the future development strategy of mountain cities. To sum up, the current research trend mainly focuses on the spatial planning of mountain cities (Mao, 2016), landscape security pattern and ecological protection $(L u, 2019)$. However, there are few theoretical studies on resilience planning and vulnerability of mountain cities.

Vulnerability is regarded as the result of multiple factors. In 1996, IPCC gave the definition of vulnerability: "Vulnerability refers to the degree of damage or injury of a vulnerable system, depending on its exposure, sensitivity and adaptive capacity (Houghton,1996)".Methods to characterize vulnerability are debated in both theory and in practice. Li Tong yue(2017) established the research framework, evaluation index system and evaluation model of "expose-sensitive-adaptation" urban vulnerability. He used principal component analysis and cluster analysis to study urban spatial vulnerability. In another method that has been used to assess vulnerability, urban disaster risk, urban vulnerability and disaster relief capacity are closely related to urban comprehensive disaster risk coefficient. Considering the disasters such as earthquake, fire, landslide and debris flow in mountain cities, the disaster risk assessment system of mountain cities is constructed (Chen. Et al.,2020), and the vulnerability optimization model of mountain cities is built on this basis. Basing on panel data from Urban Audit database and a set of newly developed indicators, Carlos Tapia. et al.,(2017) assessed urban vulnerabilities. This knowledge is a necessary step to advance in the understanding of urban risks to climate change. Besides, integrates GIS-based modelling along with a spatial multi-criteria analysis of social vulnerability, through interdisciplinary approaches that enhance less detailed datasets, which leads lead to better targeted mitigation efforts (Iuliana Armas, 2017). At present, most academic studies focus on regional and urban scales, but do not carry out vulnerability assessment on the inner and outer spatial classification of mountain cities.

Urban vulnerability refers to the ability of a city to resist the interference of internal and external natural factors, such as resources, ecological environment, economic and social development, as well as human factors in the process of development. Vulnerability assessment and analysis are crucial for resilient urban planning, which is to identify and measure the types, scope, intensity and spatial distribution of environmental risks faced by cities. However, the current study of urban vulnerability cannot meet the above objectives: (1) The accuracy of spatial pattern identification of urban vulnerability is not enough. Space is an important dimension of urban vulnerability research. Some ecological spaces outside cities are more vulnerable than other areas; (2) The pertinence of urban vulnerability research conclusions and the operability of flexible planning are not enough. The outer space of the city takes the boundary of the current built-up area as the inner boundary line, and the regional boundary directly influenced by the city as the inner boundary line. Its space covers not only the rural-urban fringe, but also urban functional areas such as urban industrial zones, satellite cities, and various development zones that the city expands outward in the form of enclaves. It is a space of interaction and intersection between urban and rural areas, and can also be understood as "urban-rural transition zone" (Li,2014) . It is necessary to protect 
the external space environment in order to fundamentally solve the problems of various urban disasters caused by climate change. Only the healthy development of the external environment can provide more ecological function support for the city, react on the urban environment and guide the healthy development of the city.

The DPSIR (Driver-Pressure-State-Impact-Response) model is a conceptual model of an evaluation index system widely used in environmental systems. It is an adaptive management tool that analyses environmental problems by establishing causal relationships between activities and environmental and socio-economic impacts (Gari, et al. 2015). The basic assumption of this framework is that social and economic developments (drives) exert pressure on the environment and lead to changes in the state of the environment -- which have potential effects and ultimately lead to social responses to drives, or directly reflected in pressures, states, or influences. The DPSIR model is introduced into the composite urban system to sort out the relationships between society, economy, resources and environment, simplify complex problems and provide a basis for more detailed analysis (NESS, et al. 2010). It can be used for research at any scale, from global scale to mountain scale. It also supports integrated, multidimensional evaluation. Wu, et al.(2019) constructed DPSIR model for three aspects of social, economic and natural factors to evaluate regional ecological security, and identified ecological sources based on multi-scale analysis of landscape connectivity. Finally, they proposed that ecological security pattern construction is an important way to guarantee urban ecological security. Zheng, et al. (2018) constructed the conceptual model of urban climate carrying capacity, the evaluation index system and evaluation model of climate carrying capacity based on the DPSIR model. They proposed weather carrying capacity and spatial adaptation method system, conducted qualitative and positioning simulation analysis of urban climate carrying capacity space, and created urban climate carrying map. Malek Mohammadi, et al.(2017)discusses wetland vulnerability in terms of analysis of human and environmental systems from application of the driver-pressure-state-impact-response (DPSIR) framework. This assessment presented a systematic methodology for assessment of wetland vulnerability in a socialecological approach to applying broad-scale ecosystem services and vulnerability functions.

In this study, the DPSIR model was used to analyse relationships and interactions between humans and the environment. The method included integrated landscape management by providing an appropriate management strategy. For this purpose, Zhao Tong, a mountainous city in southwest China, was selected as a case study. Assessment of vulnerability functions of this city have been made on the outer space using a social-ecological approach.

\section{Materials and method}

\subsection{Case study}

Zhao Tong is located in the Wu Meng Mountain area in southwest China (Fig.1), covering an area of 23,000 square kilometres and inhabited by 25 ethnic groups. The terrain is high in the southwest and low in the northeast, which is a typical structural mountainous terrain with high mountains and deep valleys. The city has an average elevation of 1685 meters, the highest elevation of 4040 meters, the lowest elevation of 267 meters, with plateau monsoon three-dimensional climate characteristics. There is little difference in four seasons. The altitude from high to low can be divided into plateau climate, temperate climate and subtropical climate. At the same altitude, the temperature in the south of Zhao Tong is higher than that in the north, and the humidity is lower than that in the north. Southwest China is one of the regions where destructive natural disasters occur frequently and earthquake disasters are particularly serious, and Zhao Tong area is one of the regions where earthquake disasters (or other natural disasters) are most serious.

\section{○ isocarp}


ZHAO, KX

Beijing, China

\section{Assessment of External Spatial Vulnerability of Mountain Cities under Climate Change: Zhao Tong Case Study, China}

The scope of urban external environment involved in this study is to facilitate the discussion of vulnerability of mountain cities. Therefore, on the basis of the previous understanding and considering the role of peripheral environment on urban space, the scope of urban external environment is an intrinsically connected natural ecological region, including natural ecological environment and urban construction points (Fig.2). Due to the interaction between urban construction sites and natural ecological environment, surrounding urban construction sites should be included. For polycentric cities, the ecological space between groups is also included (Li, 2014).

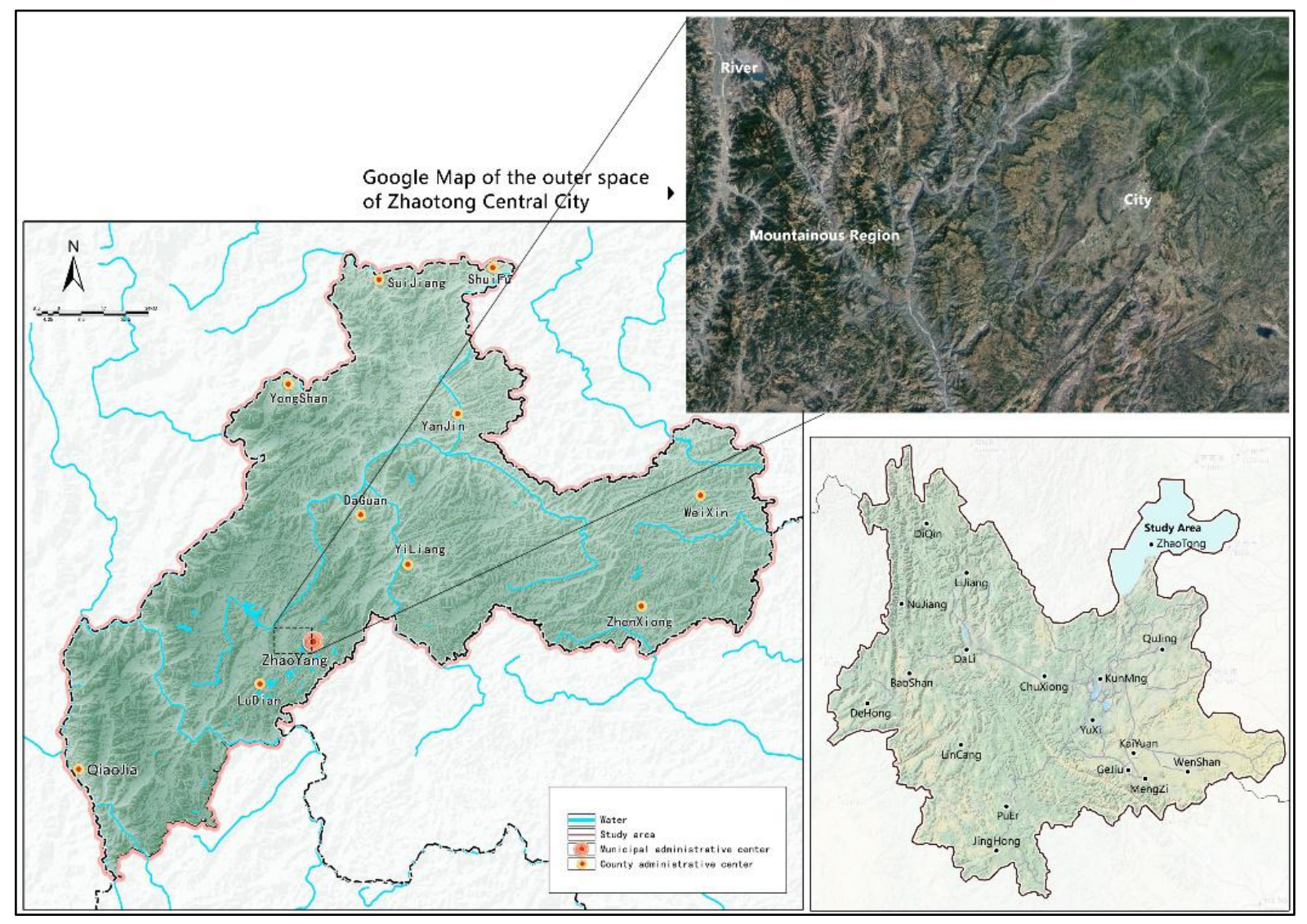

Fig. 1. Location of Zhao Tong and related landscape. Source: Author self-

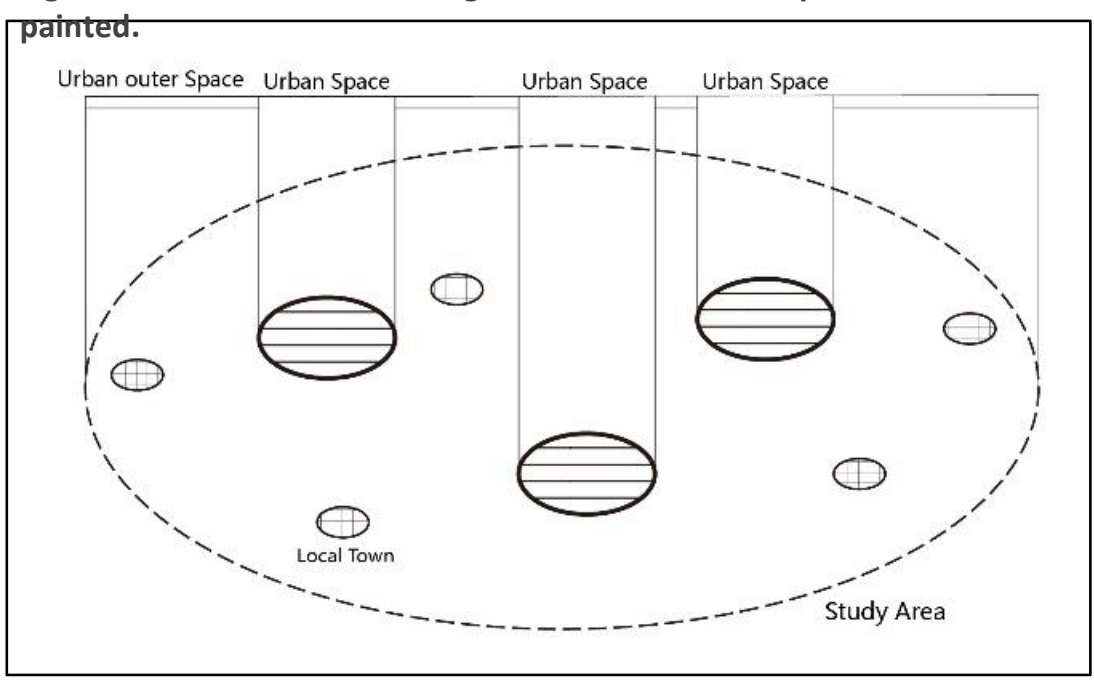

Fig. 2. The outer space of the polycentric city. Source: Li, 2014. 


\subsection{Methodology}

In this paper, a systematic framework was developed to assess vulnerability of the mountain city using a semiquantitative approach applying judgments of some experts (Fig. 3). The method follows the steps

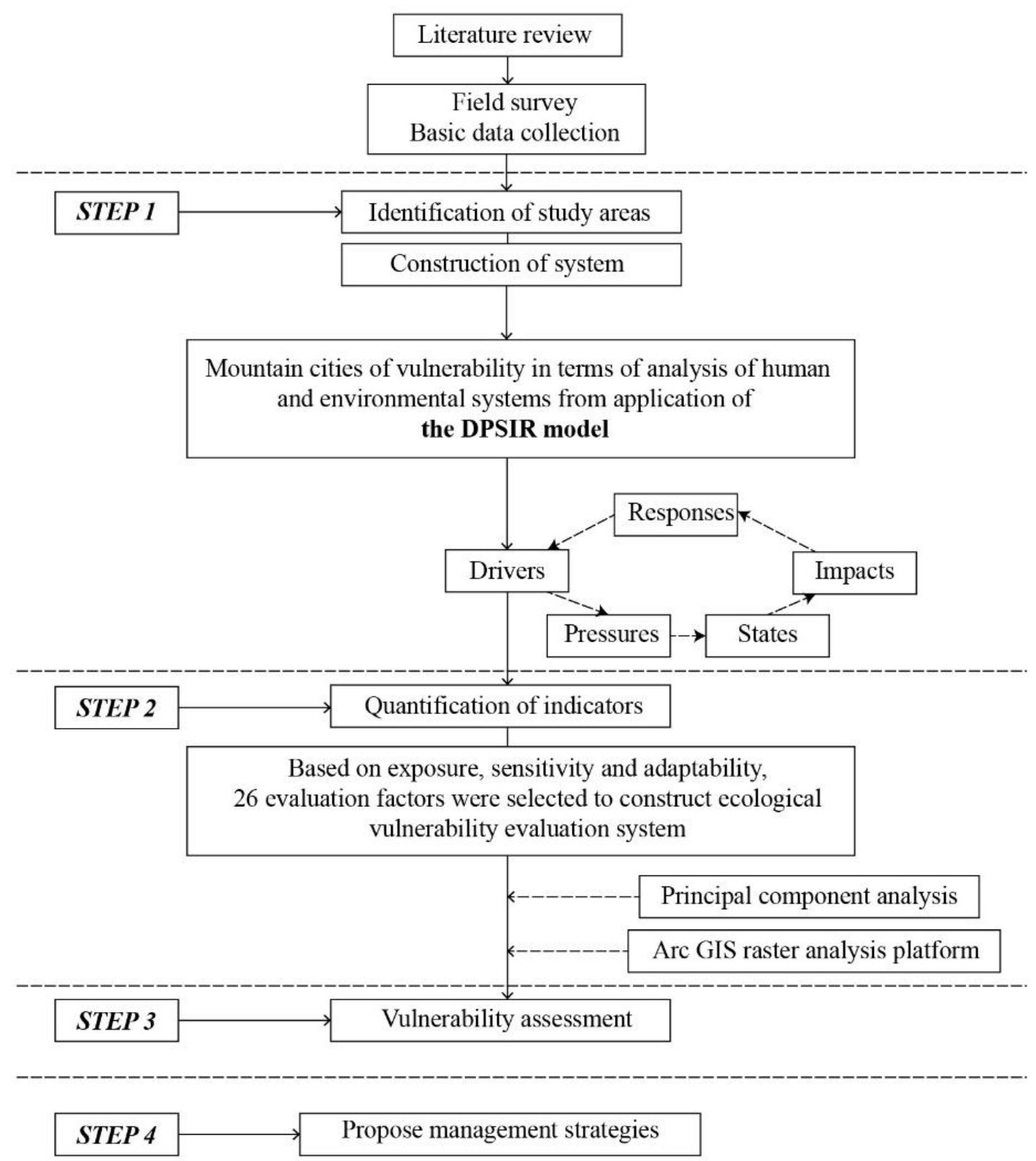

Fig. 3. Framework of the methodology. Source: Author self-painted.

listed below:

\section{Step 1: Construction of system}

The DPSIR model was applied for analysis of human interaction with the environment for characterization of the condition of the mountain city. Driver (D) refers to the forces driving social progress, economic and cultural development under climate change, including pressures caused by environmental problems, population growth, etc.; Pressure $(P)$ refers to the activity that actually causes the vulnerability of 
mountain cities under the action of driving force. State (S) refers to the condition of mountain cities after being affected by pressure; Impact (I) refers to the damage to the natural environment or social and economic losses caused by the vulnerability of mountain cities under climate change; Response (R) refers to the measures taken by human beings to enhance urban resilience and reduce vulnerability, which are mainly reflected in management and technical improvement measures. Based on the principle of the DPSIR model, the target layer was decomposed into five criteria layers, namely Driver, pressure, state, impact and response, considering social, economic and natural factors. According to the accessibility and simplicity of indicators, redundant indicators are removed, factors reflecting the main characteristics of vulnerability are selected for each criterion layer, and 4 indicators are selected to construct the evaluation indicator system.

\section{Step 2: Quantification of indicators}

To quantify drivers (threats) and impacts, indicators were taken from a review of the related literature and they included exposure, sensitivity and adaptive capacity.

Exposure: The natural background factors in the ecological environment determine the ecological base of the outer space of mountain city. Geological geomorphology, soil, hydrology and other factors are exposed. When the landscape pattern factors of land use are disturbed by the external environment, they will show spatial changes, so many factors of land use are exposed.

Sensitivity: There are sensitive factor indexes of land use, and vulnerability will be enhanced in the case of external disturbance. Most indexes in the ecological environment are directly affected by external disturbance, and there are few critical conditions caused by disturbance. Therefore, only the number and diversity of vegetation and animal population have critical value of change, and sensitivity exists.

Adaptive capacity: The external ecological environment of mountain cities includes soil, water flow, air and so on. The adaptability of these factors to pollution have a long time and slow effect in alleviating vulnerability. Therefore, the adaptability of ecological environment is more reflected in the factors of human development, such as waste treatment technology, waste utilization and ecological governance. Land use adaptability is mainly manifested in the built environment, buildings and facilities of towns outside the city.

Formula (1) is used to calculate external space vulnerability of mountain cities:

$$
V=E+S-A(1)
$$

$V$---Space vulnerability;

$E$--- exposure;

$S$--- sensitivity;

$A$--- Adaptive capacity.

\section{Step 3: Vulnerability assessment}

Based on GIS, this study discusses the application of principal Component analysis (PCA) to the evaluation of ecological vulnerability of external space in mountain cities.

Firstly, the basic data are processed by mathematical statistics, and the obtained data are transformed into a unified pasteurized graphic format, so that they are in the same coordinate system. The data are covered according to the studied spatial regions, so that the spatial overlay expression of multi-source spatial data can be realized, and the establishment of ecological vulnerability evaluation system can be realized at the same time. All the evaluation index factors used in this study were transformed into GRID mode. In the research area, the basic data obtained in the research stage are presented and 
superimposed on the unit digital grid, so as to calculate the ecological vulnerability index within the region. When the evaluation system belongs to multi-factor analysis, in order to objectively reflect the different importance of each factor to the evaluation target, certain mathematical methods are generally used to determine the weight of factors. Principal component analysis is a method to select several groups of important variables from multiple evaluation variables through a linear transformation for statistical analysis (Banica, et al. 2017). When selecting evaluation variables, in many cases, variables are correlated to a certain extent, and there will be certain data overlap between these variables. The purpose of principal component analysis is to reduce new variables as far as possible, reduce the correlation between them, or even reach the degree of separation, and maintain their original information content, so as to reduce the influence of artificially determined evaluation indicators in the evaluation process.

The correlation between ecological vulnerability and evaluation indexes shows two trends, that is, positive correlation and negative correlation. Positive correlation means that the larger the evaluation index value is, the greater the vulnerability of ecological environment will be. Negative correlation is the same and opposite. The larger the index value is, the smaller the vulnerability of ecological environment is. While standardizing the indexes, evaluation indexes with different correlations with ecological vulnerability need to be unified by different range formulas. When there is a negative relationship between ecological vulnerability and evaluation index, formula (2) is used. When there is a positive relationship between ecological vulnerability and evaluation indexes, formula (3) is used (Chen,2015).

$$
\begin{gathered}
p_{i}=\left[1-\left(x_{i}-x_{i \min }\right) /\left(x_{i \max }-x_{i \min }\right)\right. \\
p_{i}=\left(x_{i}-x_{i \min }\right) /\left(x_{i \max }-x_{i \min }\right)
\end{gathered}
$$

$P_{i}$ is the standardized value of grade $i$ of a variable factor, $x_{i}$ is the initial value of grade $i$ of the variable factor; $x_{i m i n}$ is the minimum value of this variable factor in the study area; $x_{\text {imax }}$ is the maximum value of this variable factor in the study area.

\section{Step 4: Propose management strategies}

Finally, regarding prioritization of threats and vulnerability values of mountain city, appropriate environmental management strategies were provided according to the DPSIR framework.

\section{Results}

The results are presented same as the steps in the methodology as follows:

\section{Step 1: Construction of system}

The research framework based on the DPSIR model is shown in Table 1.

Table 1

Applying the DPSIR model to human and environmental systems of Zhao Tong

\begin{tabular}{cccc}
\hline Driver & Pressure & State & Impact \\
\hline Natural disasters & - Earthquake and its & - Government and & - Economic losses \\
Agricultural & -Drainage of the agricultural & -Increasing in organic and & - Casualties \\
activities & -Uncontrolled development & inorganic contaminants & - Mountain environment \\
& of fields & pollution & - Reduction of ecological \\
Settlements and & - Land use change and & space & - Reducing habitats
\end{tabular}




\begin{tabular}{|c|c|c|c|}
\hline \multirow{3}{*}{ Population Growth } & & $\begin{array}{l}\text {-Disturbing the biological } \\
\text { balance }\end{array}$ & \\
\hline & - Excessive deforestation & $\begin{array}{l}\text { - Habitat loss and increase } \\
\text { flooding potential }\end{array}$ & $\begin{array}{l}\text { - Reducing habitat and } \\
\text { breeding continuity }\end{array}$ \\
\hline & - Urban sprawl & - Decline in species richness & $\begin{array}{c}\text { - Reducing the educational } \\
\text { opportunities }\end{array}$ \\
\hline
\end{tabular}

\section{Step 2: Quantification of indicators}

The change of the index will increase or decrease the external spatial vulnerability of mountain cities. For example, the increase of the density of geological hazards will increase the vulnerability, while the increase of vegetation coverage will decrease the vulnerability. In this study, research indicators were classified according to exposure, sensitivity and adaptive capacity, as showed in Table 2-4.

Table 2

Exposure factors and indexes of external space in mountain cities

\begin{tabular}{|c|c|}
\hline Exposure factors & Indexes \\
\hline Terrain & $\begin{array}{l}\text { Slope, land degradation area, humus layer thickness, erosion } \\
\text { rate }\end{array}$ \\
\hline Hydrological & $\begin{array}{l}\text { Runoff width, flow rate, self-cleaning capacity, number of } \\
\text { sewage outlets, diffusion rate }\end{array}$ \\
\hline Climate & $\begin{array}{l}\text { Rainfall, temperature, frost-free days, air pollution index III or } \\
\text { above days, meteorological disasters caused losses }\end{array}$ \\
\hline Vegetation & Vegetation coverage \\
\hline Animal & Distance between main habitat and settlement \\
\hline Hidden danger of natural disaster & Number of hidden trouble points, occurrence frequency and loss \\
\hline Natural disaster loss & $\begin{array}{l}\text { Frequency of earthquake, landslide, debris flow, disaster area, } \\
\qquad \text { loss degree }\end{array}$ \\
\hline Construction land & $\begin{array}{l}\text { Area and proportion of township construction land in the outer } \\
\text { space of mountain cities }\end{array}$ \\
\hline Arable land, & Area and proportion of commonly used arable land \\
\hline River (Wetland) & Area and proportion of watersheds (wetlands) \\
\hline Woodland & Forest area and proportion, forest coverage rate \\
\hline The grass & Grassland area and proportion, grassland desertification area \\
\hline Construction and development intensity & $\begin{array}{l}\text { The average plot ratio of township units and the proportion of } \\
\text { residential area to homestead area }\end{array}$ \\
\hline
\end{tabular}

Table 3

Sensitivity factors and indexes of external space in mountain cities

\begin{tabular}{|c|c|}
\hline Sensitivity factors & Indexes \\
\hline $\begin{array}{l}\text { Vegetation population } \\
\text { diversity }\end{array}$ & Number of plant species, number and proportion of various groups \\
\hline $\begin{array}{l}\text { Animal population } \\
\text { diversity }\end{array}$ & Number of animal species, number and proportion of various groups \\
\hline $\begin{array}{l}\text { Fragmentation of } \\
\text { landscape structure }\end{array}$ & Patch types, quantity, spatial proportion and spatial distribution in the region \\
\hline $\begin{array}{l}\text { Built-up spatial } \\
\text { distribution }\end{array}$ & Number, area, spatial distribution and spatial proportion of villages and towns \\
\hline $\begin{array}{l}\text { Types and } \\
\text { characteristics of built- }\end{array}$ & $\begin{array}{l}\text { The number and area of industrial and mining enterprises in towns, the age } \\
\text { and damage degree of residential buildings }\end{array}$ \\
\hline
\end{tabular}



up space buildings
Material culture protection
Intangible cultural protection
The number and proportion of traditional villages, the number and degree of preservation of historical buildings
Number and proportion of preservation of rural legends, folk activities and traditional skills

Table 4

Adaptive capacity factors and indexes of external space in mountain cities

\begin{tabular}{|c|c|}
\hline Adaptive capacity factors & Indexes \\
\hline $\begin{array}{l}\text { Introduction of sewage treatment } \\
\text { technology }\end{array}$ & $\begin{array}{l}\text { Number of sewage treatment plants and waste } \\
\text { treatment plants, number of days of air quality ii } \\
\text { standard }\end{array}$ \\
\hline $\begin{array}{c}\text { Introduction of ecological governance } \\
\text { technologies }\end{array}$ & $\begin{array}{l}\text { Soil erosion control rate, degraded land control rate, } \\
\text { salinization control rate }\end{array}$ \\
\hline $\begin{array}{l}\text { Introduction of waste utilization } \\
\text { technology }\end{array}$ & $\begin{array}{l}\text { Comprehensive utilization rate of straw and manure in } \\
\qquad \text { farm }\end{array}$ \\
\hline Prevention and control engineering & $\begin{array}{l}\text { Number of prevention and control projects and related } \\
\text { facilities }\end{array}$ \\
\hline New arable land, woodland & $\begin{array}{l}\text { The proportion of cultivated land area increase, } \\
\text { woodland area increase }\end{array}$ \\
\hline $\begin{array}{l}\text { Roads and municipal facilities, public } \\
\text { service facilities }\end{array}$ & $\begin{array}{l}\text { Length of county roads and township roads, hardening } \\
\text { rate of village roads, penetration rate of tap water, } \\
\text { penetration rate of gas, connectivity rate of Internet, } \\
\text { ratio of existing public facilities to standard facilities }\end{array}$ \\
\hline
\end{tabular}

\section{Step 3: Vulnerability assessment}

The ecological vulnerability evaluation system constructed by multiple indicators will make the vulnerability evaluation more comprehensive, and at the same time, attention should be paid to the different strength of the impact of different indicators on environmental vulnerability. In the evaluation of vulnerability, it is a very important step to determine the weight of each index reasonably according to the different influence of intensity. The raster analysis platform of ArcGIS provides great convenience for data modelling. The technical steps are as follows :(1) unify the obtained sub-graphs of standardized evaluation indexes into raster data under a spatial coordinate system; (2) Using principal component analysis (PCA) function to carry out weight analysis; (3) The comprehensive vulnerability score of the study area was calculated through map algebra operation, and the research results were analysed and expressed visually, so as to obtain the ecological vulnerability analysis graph (Fig.4).

Table 5

Evaluation index system of Zhao Tong external space ecological vulnerability based on the DPSIR model

\begin{tabular}{ccccc}
\hline Driver & $\begin{array}{c}\text { Classification } \\
\text { indexes }\end{array}$ & Number & Specific indexes & Weight \\
& & 1 & Hidden danger of natural disaster & 0.045 \\
Natural & Exposure factors & 3 & Natural disaster loss & 0.037 \\
disasters & & 4 & Terrain & 0.110 \\
& & 5 & Hydrological & 0.038 \\
& & 6 & Climate & 0.065 \\
& & 7 & Vegetation & 0.025 \\
& & Animal & 0.025
\end{tabular}




\begin{tabular}{|c|c|c|c|c|}
\hline & Exposure factors & 9 & Water Body (Wetland) & 0.100 \\
\hline & & 10 & Woodland & 0.038 \\
\hline \multirow{8}{*}{$\begin{array}{l}\text { Agricultural } \\
\text { activities }\end{array}$} & & 11 & The grass & 0.020 \\
\hline & Sensitivity factors & 12 & Fragmentation of landscape structure & 0.060 \\
\hline & & 13 & Introduction of sewage treatment & 0.025 \\
\hline & Adaptive capacity & & technology & \\
\hline & factors & 14 & $\begin{array}{c}\text { Introduction of ecological governance } \\
\text { technologies }\end{array}$ & 0.025 \\
\hline & & 15 & $\begin{array}{l}\text { Introduction of waste utilization } \\
\text { technology }\end{array}$ & 0.025 \\
\hline & & 16 & Prevention and control engineering & 0.025 \\
\hline & & 17 & Vegetation population diversity & 0.035 \\
\hline \multirow{6}{*}{$\begin{array}{l}\text { Settlements } \\
\text { and urban } \\
\text { areas }\end{array}$} & & 18 & Animal population diversity & 0.035 \\
\hline & Sensitivity factors & 19 & Built-up spatial distribution & 0.030 \\
\hline & & 20 & $\begin{array}{l}\text { Types and characteristics of built-up } \\
\text { space buildings }\end{array}$ & 0.020 \\
\hline & & 21 & Material culture protection & 0.020 \\
\hline & & 22 & Intangible cultural protection & 0.020 \\
\hline & Exposure factors & 23 & Construction land & 0.032 \\
\hline Population & & 24 & Construction and development intensity & 0.045 \\
\hline \multirow[t]{2}{*}{ Growth } & Adaptive capacity & 25 & New arable land, woodland & 0.038 \\
\hline & factors & 26 & $\begin{array}{l}\text { Roads and municipal facilities, public } \\
\text { service facilities }\end{array}$ & 0.032 \\
\hline
\end{tabular}

Through the calculation and analysis of ecological vulnerability rating model, Zhao Tong external space vulnerability status is obtained. The smaller the ecological vulnerability index is, the smaller the ecological vulnerability degree is. As can be seen from Figure 4, there are obvious differences in ecological fragility in Zhao Tong. Based on the natural geography and vulnerability characterization of the study area, the ecological vulnerability of the study area is divided into three levels: mild vulnerability, moderate vulnerability and severe vulnerability.

The characteristics of various ecological vulnerability grades are as follows: (1) Mild vulnerability: the ecological environment of this region is good, the system is stable, species are abundant, vegetation community structure is stable, human factors are small, pressure from the outside is small, and antiinterference ability is strong. (2) Moderate vulnerability: the vegetation in the region is reduced, mostly in the transition zone from forest area to human settlement land, with a large reduction of species, a small number of ecological abnormalities, certain man-made destruction behaviours in the region, high external pressure, reduced stability of vegetation community structure, low anti-interference ability. (3) severe vulnerability: the ecosystem in this region is in an unstable stage, with many abnormal ecological conditions, vegetation evacuation, unstable vegetation community structure, serious human interference, fragmentation of landscape patches, and great external pressure. The utilization and transformation of land by human beings have increased, and species have decreased sharply. Moreover, the ecological selfresilience is low and the anti-interference ability is poor.

\section{Step 4: Propose management strategies}

In the future urban development, we should build a network of green corridors to connect all points and surface green spaces, form a good ecological environment, introduce fresh air into towns and promote air circulation. The construction and protection of protection green space and regional green space should be strengthened. These two types of green space occupy an important position in mountain cities, 
with wide distribution and large proportion, and play an important role in urban ecological construction. Construction of protective green space layout is mainly based on preliminary analysis to protect mildly vulnerable areas. Production green land is mainly forest land, for the future agricultural land to leave enough space for development. In addition, due to topographical reasons, Zhao Tong has many hidden dangers of geological disasters, such as landslides, debris flows, ground cracks and other frequent phenomena, and some rural areas are in moderate strength vulnerable areas. It is suggested that the

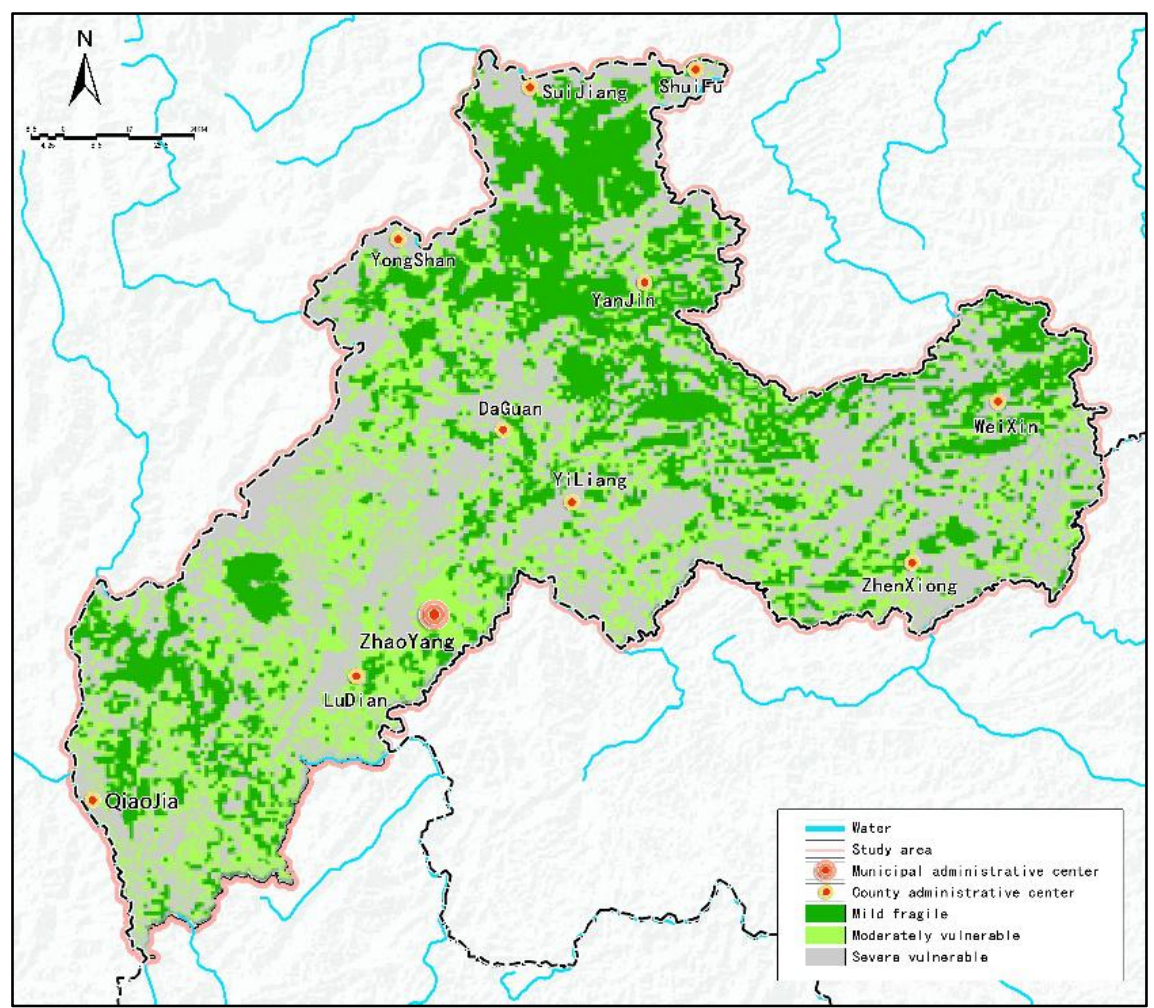

Fig. 4. Ecological vulnerability analysis of Zhao Tong. Source: Author self-painted.

rural residential areas in moderate strength vulnerable areas should be moved out gradually in the planning.

\section{Discussion}

The conceptual framework of the DPSIR model was used to organize environmental information and relationships between the environmental indicators of human activity and the set of ecosystem services.

According to the statistical analysis of the changes of NDVI index in Zhao Tong from 1998 to 2018, the ecological quality of most regions has improved significantly $77 \%$ of the areas with NDVI change of more than 0.1). The decrease in some regions is due to the decrease of vegetation index caused by urbanization, such as Zhao Yang District, Zhen Xiong, Shui Fu, etc. The central area of each county appeared different degrees of reduction. The weight of each evaluation index of mountain city was obtained through spatial principal component analysis. The analysis of the weight system of each index shows that, among the vulnerability evaluation indexes, the weight value of exposure factor is larger, indicating that topography, hydrology climate and other factors of mountain city have a greater impact on regional ecological vulnerability, followed by sensitivity factor. The effects of vegetation population diversity, animal population diversity, built-up space and other indicators on ecological environment 
were relatively balanced, indicating that the complexity of landscape pattern, forest vegetation and altitude environment all played an important role in ecological vulnerability.

The vulnerability in the northern and southwestern parts of Zhao Tong mainly belongs to the weak intensity, and its land type is mainly mountainous and hilly areas with sparse population distribution. As a whole, Zhao Tong has a good forestry foundation and a good ecological environment foundation, and the rapid development of urban economy is also the basis for ecological forestry protection. Zhao Tong has continuously increased investment in forest resources protection, increased protection efforts, and vigorously protected forest disasters. Meanwhile, the phenomenon of deforestation is strictly prohibited. These measures are the feedback for the ecological environment, so that Zhao Tong maintains a moderately fragile status quo. But at the same time, Zhao Tong also has the function and form of a mature town. With the continuous development of economy and the growth of population, the disturbance of social factors to its ecological environment will continue to deepen. How to effectively and pertinently analyse and protect the ecological environment is an important means to adhere to sustainable development.

\section{Conclusions}

First of all, the external spatial database of Zhao Tong city was established by field investigation and acquisition of basic data in the study area, combined with extraction of spatial image data, etc., to lay a foundation for further ecological research. Secondly, ecological vulnerability of Zhao Tong was analysed and evaluated. With the aid of DPSIR model, three factors both social - economic - natural, full consideration Zhao Tong unique topography and land use factors, the target layer is decomposed into driver, pressure, state, impact and response rule of five layers, the four indexes to construct the evaluation index system, and from the exposure, sensitivity and adaptability of three factors, Comprehensive selection of geomorphology, hydrology, climate, vegetation, animals, cultivated land, water, wetland, forest land 26 evaluation factor of ecological vulnerability of Zhao Tong evaluation system, the application of spatial principal component analysis method, based on superposition of spatial data analysis, evaluation system will pick several main factor, and for the construction of evaluation system of the final weight factor analysis to extract. Then, ecological vulnerability of Zhao Tong was evaluated by combining the evaluation theory of ecological vulnerability and the spatial overlay method of evaluation technology, and the ecological vulnerability of Zhao Tong's external space was obtained. Finally, based on the analysis of the evaluation results of ecological vulnerability in Zhao Tong and the problems of ecological status, combined with the current situation of urban construction in Zhao Tong and the conditions of natural landscape resources and other factors, different protection ideas are put forward for Zhao Tong 's ecological vulnerability areas.

\section{Funding}

This research has received funding from the National Natural Science Foundation of China and The Science and Technology Program of Ministry of Housing and Urban-rural Development of the People's Republic of China.

\section{Acknowledgements}

The team is thankful to The Chinese Academy of Sciences.

\section{U isocarp}




\section{References}

Armaş, I., Toma-Danila, D., Ionescu, R., \& Gavriş, A. (2017). Vulnerability to earthquake hazard: Bucharest case study, Romania. International journal of disaster risks science, 8(2), 182-195.

Banica, A., Rosu, L., Muntele, I., \& Grozavu, A. (2017). Towards urban resilience: A multi-criteria analysis of seismic vulnerability in lasi City (Romania). Sustainability, 9(2), 270.

CHEN Xuanxian, WANG Peiming \& FU Zhiguo.(2020). Study on layout optimization of fixed refuge in mountainous city based on disaster risk assessment-Take Dong chuan district for example[J]. Journal of Natural Disaster (01),162-174. doi:10.13577/j.jnd.2020.0117.

Chen Yao. (2015). The green space system layout research based on ecological vulnerability evaluation of Longshan Town (Master's thesis, Zhejiang A\&F University).

GARI S R, NEWTON A, ICELY J D. A review of the application and evolution of the DPSIR framework with an emphasis on coastal social-ecological systems[J]. Ocean \& coastal management, 2015, 103: 63-77.

Houghton, J. T., Meira Filho, L. G., Callander, B. A., Harris, N., Kattenberg, A., \& Maskell, K. (1996). IPCC climate change. The IPCC second assessment report.

Huang Ling \& Peng Xiang.(2017). Creating Open And Shared Space In Urban Renewal Of Mountainous City[J]. Planners(7):38-43. doi:CNKI:SUN:GHSI.0.2017-07-006.

Huang Ling, Ming Junyu, Zhao Chang \& Song Chunpan.(2019). The Character Analysis and Planning Strategy of Community Life Circle in Mountainous Cities[J]. Planners(03),11-17. doi:CNKI:SUN:GHSI.0.2019-03-002.

Li Chan.(2016). Policy of Rural Planning and Design in Earthquake-prone Regions(Master's thesis, Kunming University of Science and Technology).

Li Tongyue. (2017). Spatial Vulnerability Based on the Framework of the Exposure-Sensitivity-Adaptive Capacity :A Case Study of Lanzhou[J]. Economic Geography (03),86-95. doi:10.15957/j.cnki.jjdl.2017.03.012.

Li yunyan. (2014). Study on Theories and Methods of Urban Space Adapt to Disaster in Southwest Mountainous Cities. (Doctor's thesis, Chongqing University).

Li Zheng \& Li Xiong. (2016). How to Study Hillside Development and Protection in the Context of Urbanization: A Review of English Literature Concerning Research Methods and Technology[J]. Chinese Landscape Architecture(04),62-67. doi:CNKI:SUN:ZGYL.0.2016-04-011.

Lu Tao, Peng Yaoling, He Bo, Liu Jian \& Wen Wei.(2019). Ecology Oriented Urban Agglomeration Spatial Planning of Northeastern Chongqing City[J]. Planners (18),68-74. doi:CNKI:SUN:GHSI.0.2019-18-011

Malek Mohammadi, B., \& Jahan Shakib, F. (2017). Vulnerability assessment of wetland landscape ecosystem services using driver-pressure-state-impact-response (DPSIR) model. Ecological Indicators, 82, 293-303.

Mao Zhuoying \& Mao Yalong.(2016). Fractal Thinking about Mountainous Town Planning[J]. Mountain Research(02),223-232. doi:10.16089/j.cnki.1008-2786.000122.

Ness, B., Anderberg, S., \& Olsson, L. (2010). Structuring problems in sustainability science: The multi-level DPSIR framework[J]. Geoforum, 41(3), 479-488.

Saaty, T.L., 2008. Decision making with the analytic hierarchy process. Int. J. Serv. Sci. 1, 83-98. 
Wang Jun. (2015). Ecological Strategy of Mountainous City Underground Space Planning[J]. Chinese Journal of Underground Space and Engineering (S1),1-6. doi:CNKI:SUN:BASE.0.2015-S1-001.

Wu Maoquan, Hu Mengmeng, Wang Tao, Fan Chen \& Xia Beicheng.(2019). Recognition of urban ecological source area based on ecological security pattern and multi - scale landscape connectivity[J]. Acta Ecologica Sinica, 39( 13) : 4720-4731.

Yu Kongjian, Yuan Hong, Li Dihua, Wang Sisi \& Qiao Qing.(2009). Difficulties and Solutions of the Sustainable Land Use Strategy in Suburban Hilly Area in Beijing[J]. China Land Science(11),3-8+20. doi:CNKI:SUN:ZTKX.0.2009-11-002.

ZHENG Kaixiong, YUN Yingxia \& CHANG Wei. (2018). Research on the "Climate Capacity- Spatial Adaptation "Method in Coastal Cities: Simulation Analysis of Climate Carrying Capacity in Xiamen[J]. Urban Development Studies(08),51-58+82. doi:CNKI:SUN:CSFY.0.2018-08-008. 